\title{
A sideways look at conservation and consistency in tourism policy
}

Amy Dickman. Wildlife Conservation Research Unit, Department of Zoology, University of Oxford, The Recanati-Kaplan Centre, Tubney House, Tubney, Oxon OX13 5QL

Amy.dickman@zoo.ox.ac.uk (correspondence author)

Craig Packer. Department of Ecology, Evolution and Behavior, University of Minnesota, St Paul, Minnesota, 55108, USA.

Paul J. Johnson. Wildlife Conservation Research Unit, Department of Zoology, University of Oxford, The Recanati-Kaplan Centre, Tubney House, Tubney, Oxon OX13 5QL

David W. Macdonald. Wildlife Conservation Research Unit, Department of Zoology, University of Oxford, The Recanati-Kaplan Centre, Tubney House, Tubney, Oxon OX13 $5 \mathrm{QL}$

\section{Article Impact Statement}

U.S. restrictions on importing trophies from hunted lions may not help conservation and are based on an unacknowledged double standard.

Running head: Consistency and Wildlife Tourism 
Consistency is widely believed to be a virtue: in Dante's inferno, some of the hottest fires of hell are reserved for hypocrites. Inconsistencies in attitudes toward wildlife are legion (Herzog 2011). One concerning wild lions (Panthera leo) prompts an illuminating thought experiment. Following the trophy hunting of Cecil the lion in 2015, there were widespread calls for banning trophy hunting (Nicholls 2015). The furore highlightedpublic enthusiasm for lion conservation, stimulated interest in the management of land where lions persist, and may have lessons for wildlife management more widely.

Also in 2015, the African lion was listed under the U.S. Endangered Species Act, and the U.S. Fish and Wildlife Service (USFWS) now permits the import of lion trophies only from areas where hunting benefits conservation. The rationale is that many U.S. lion hunters (currently the majority of lion hunters) are likely to stop hunting if they cannot export their trophies. This restriction provides an incentive for hunting operators to fulfil the prescribed requirements. The burden of proof is considerable. Operators need to demonstrate population monitoring and "scientifically based management programs" and are required to show local people benefit. There is a sound case for requiring hunting operators to demonstrate, at least, that they are not contributing to lion decline. This principle (that operators demonstrate "nondetriment," currently a requirement of CITES Appendix II listing) might be applicable to any wildlife-based land use. Consider phototourism, another land use that in some places depends on lions. The greatest contribution of both activities to conservation is arguably that they can prevent conversion of habitat to nonwildlife based land uses (Macdonald 2016). Our intention is not to compare the impacts of phototourism and trophy hunting (many of which are unknown and differ geographically), but rather to consider whether they should be treated with the same principles. Equal accountability and independent assessment are important where land is managed for wildlife, particularly where corruption is rife. Both land uses 
occur where lions are declining, where there can be many possible causes for their predicament, and where there is geographic variation and abundant knowledge gaps.

Both have the potential to benefit lion conservation and to be inimical to it. Trophy hunting can be bad for lion populations (Packer et al. 2011; Loveridge et al. 2016). It is indisputable that some lion populations subjected to trophy hunting are declining (Bauer et al. 2016), and the most severe declines are likely to be the least monitored (Bauer et al. 2015). There are, however, many possible causes, and the contribution of trophy hunting is frequently unclear (Macdonald et al. 2017). We believe hunting should be reformed wherever there is evidence it is detrimental to lion conservation. Where reform is not possible and there are decisive reasons to believe it contributes to decline in lion numbers, it should be stopped.

Phototourism can also be bad for lions, although clearly less dramatically so. Poorly managed tourism has been linked with habitat degradation, poaching of prey, and humanwildlife conflict(Cater 1993). Tourists can stress lions (Hayward \& Hayward 2009). A recent account of badly run tourism in the Masai Mara suggests this land use should be regulated (Allan 2017). Lion numbers are declining in most phototourism areas (Bauer et al. 2016), and, as is the case for hunting areas, it is not always clear whether phototourism is contributing to that decline. Badly managed trophy hunting can act more directly and quickly than badly managed tourism to deplete numbers, and neither the immediate nor the long-term impacts of irresponsible phototourism are as radical as those of irresponsible hunting. At one extreme, particularly where corruption prevails, numerous poorly managed hunting blocks have been abandoned because of declines in wildlife numbers (Packer 2015). Trophy hunting may be more likely have population-level negative effects. However, this distinction in how 
directly these activities can act does not, by itself, provide a good reason for conservationists to apply different standards to how they do act to promote conservation.

Trophy hunting and phototourism are not, of course, morally equivalent (motivation and participants have little in common), and making a different ethical judgement where lions are killed for sport cannot be said to constitute hypocrisy. Many people, perhaps especially in the global north, regard lion hunting as unacceptable whatever its consequences for conservation or livelihoods. We speculate this view may soon prevail (Macdonald et al. 2016a). The value of lions constitutes more than their commercial utility (Vucetich \& Macdonald 2017). Phototourism is not devoid of these ethical problems: managing lions for tourism can involve culling surplus individuals (Miller et al. 2013). However, the conditions for permitting import of lion trophies are aimed at promoting sustainability and do not take an ethical stance on trophy hunting (U.S. Fish and Wildlife Service 2015).

Despite the problems associated with trophy hunting, we question whether calls for banning it in the absence of alternative incentives to tolerate lions are in the interests of their conservation (Macdonald et al. 2016b). Trophy hunting may be the only available option for giving lions monetary value in areas where phototourism is unlikely to be financially viable. Hunters are willing to visit less accessible and less aesthetically attractive areas (Lindsey et al. 2006; Mbaiwa 2017). The most important question for conservation is how would lions fare under a different regime? The answer depends partly on incentives to value wildlife. It may be possible to substitute phototourism for trophy hunting such that habitat conversion does not result (an outcome we describe as ideal [Macdonald 2016]). But seemingly this substitution is not possible everywhere at present In Botswana, where attempts have been made to replace trophy hunting (banned since 2014) with phototourism, local attitudes toward wildlife have deteriorated as revenue is lost (Mbaiwa 2017). Where this is likely to happen was anunknown highlighted by Macdonald et al. (2017). 
The USFWS (2015) states that "For species such as the lion to persist, local communities must benefit from or receive a percentage of funds generated from tourism such as wildlife viewing , photography or trophy hunting." This is currently translated into policy only for trophy hunting and not for phototourism. Where phototourism is viable (e.g., in parts of Botswana and elsewhere), most of the revenue generated may not stay with the community (Rylance \& Spenceley 2017). In Namibia both phototourism and hunting contribute substantially to the economies of rural communities. The beneficiaries are different, however; phototourism generates employment and wages, whereas income from trophy hunting supports governance structures and management (Naidoo et al. 2016). Our purpose here is not to generalize about the benefits provided to local communities provided by either trophy hunting or phototourism; thedata are not available to do that. How trophy hunting and phototourism compare across Africa in their contribution to the well-being of local people is unclear. Our purpose is to highlight whether a regulatory principle provoked by trophy hunting should consistently be borne in mind when considering wildlife-based land uses. In 2016 the International Union for Conservation of Nature established green-list standards for protected areas aimed at ensuring good practice in phototourism areas (https://www.iucn.org/theme/protected-areas/our-work/iucn-green-list/3-green-list-areas). The voluntary scheme promotes "fair and transparent sharing of the costs and benefits of conservation, effective management and long-lasting conservation outcomes." The scheme standards do not deal specifically with possible negative effects of phototourism (or other forms of tourism) but could be adapted to do so. Wanger et al. (2017) propose a certification scheme for trophy hunting, which again could be adapted to phototourism. 
Organizations such as USFWS and CITES currently promote lion conservation by restricting the international movement of animal parts. They cannot restrict the analogous products of the phototourism industry: the countless images of lions exported from Africa every year. Yet stripped of pragmatic constraints, the logic of their current position, if applied consistently across the tourist industry, suggests support in principle for such a restriction. We believe this reductio ad absurdum exposes a double standard. We do not of course advocate restricting the movement of lion images, but we raise the question of whether certification of phototourism or any other wildlife-based land use should be based on similar standards, taking the possibility of perverse outcomes into account. Given the undisputed primacy of habitat loss, prey loss, and conflict with people as threats to lions (IUCN 2006b, a; Lindsey et al. 2017), and having used lions as an example, we advocate working with all legal wildlife tourist operations, consumptive or nonconsumptive, to ensure the continued protection of extensive rangeland for all wildlife and lions in particular.

\section{Acknowledgments}

We acknowledge useful and stimulating discussions with S. Baker, D. Burnham, L. Harrington, R. Feber, B. du Preez, and M. Stanley-Price. The manuscript also benefitted from constructive criticism provided by 2 anonymous reviewers.

\section{Literature Cited}

Allan I. 2017. Kenya's wildlife 'freakshow'. SWARA. East African Wildlife Society, city. Bauer H, Chapron G, Nowell K, Henschel P, Funston P, Hunter LTB, Macdonald DW, Packer C. 2015. Lion (Panthera leo) populations are declining repidly across Africa, 
except in intensively managed areas. Proceedings of the National Academy of Sciences of the United States of America 112:14894-14899.

Bauer H, Packer C, Funston FP, Henschel P, Nowell K. 2016. Panthera leo. The IUCN Red list of Threatened Species. International Union for Conservation of Nature , Gland, Switzerland.

Cater E. 1993. Ecotourism in the third world: Problems for sustainable tourism development. Tourism Management 14:85-90.

Hayward MW, Hayward GJ. 2009. The impact of tourists on lion Panthera leo behaviour, stress and energetics. Acta theriologica 54:219-224.

Herzog H 2011. Some we love, some we hate, some we eat. Harper Collins, New York.

IUCN (International Union for Conservation of Nature ). 2006a. Conservation strategy for the lion in West and Central Africa. IUCN, Gland, Switzerland.

IUCN. 2006b. Regional conservation strategy for the lion Panthera leo in Eastern and Southern Africa. Gland, Switzerland.

Lindsey P, Petracca L, Funston P, Bauer H, Dickman A, Everatt K, Flyman M, Henschel P, Hinks A, Kasiki S. 2017. The performance of African protected areas for lions and their prey. Biological Conservation 209:137-149.

Lindsey PA, Alexander R, Frank LG, Mathieson A, Romanach SS. 2006. Potential of trophy hunting to create incentives for wildlife conservation in Africa where alternative wildlife-based land uses may not be viable. Animal Conservation 9:283-291.

Loveridge AJ, Valeix M, Chapron G, Davidson Z, Mtare G, Macdonald DW. 2016. Conservation of large predator populations: Demographic and spatial responses of African lions to the intensity of trophy hunting. Biological Conservation 204, Part B:247-254. 
Macdonald DW. 2016. Report on lion conservation with particular respect to the issue of trophy hunting . WildCRU, Oxford. Avialble from https://www.wildcru.org/wpcontent/uploads/2016/12/Report_on_lion_conservation.pdf (accessed December $\underline{2017) .}$

Macdonald DW, Jacobsen KS, Burnham D, Johnson PJ, Loveridge AJ. 2016a. Cecil: a moment or a movement? Analysis of media coverage of the death of a lion, Panthera leo. Animals 6.

Macdonald DW, Johnson PJ, Loveridge AJ, Burnham D, Dickman AJ. 2016b. Conservation or the Moral High Ground: Siding with Bentham or Kant. Conservation Letters 9:307308.

Macdonald DW, Loveridge AJ, Dickman AJ, Johnson PJ, Jacobsen KS, Du Preez B. 2017. Lions, trophy hunting and beyond, known unknowns and why they matter. Mammal Review 47:247-253.

Mbaiwa JE. 2017. Effects of the safari hunting tourism ban on rural livelihoods and wildlife conservation in Northern Botswana. South African Geographical Journal:1-21.

Miller S, Bissett C, Burger A, Courtenay B, Dickerson T, Druce D, Ferreira S, Funston P, Hofmeyr D, Kilian P. 2013. Management of reintroduced lions in small, fenced reserves in South Africa: an assessment and guidelines. South African Journal of Wildlife Research 43:138-154.

Naidoo R, Weaver LC, Diggle RW, Matongo G, Stuart-Hill G, Thouless C. 2016. Complementary benefits of tourism and hunting to communal conservancies in Namibia. Conservation Biology 30:628-638.

Nicholls H. 2015. Charismatic lion's death highlights struggles of conservation scientists. Nature. doi:10.1038/nature.2015.18101 July 292015 
Packer C 2015. Lions in the balance : man-eaters, manes, and men with guns. University of Chicago Press, Chicago.

Packer C, Brink H, Kissui B, Maliti H, Kushnir H, Caro T. 2011. Effects of trophy hunting on lion and leopard populations in Tanzania. Conservation Biology 25:142-153.

Rylance A, Spenceley A. 2017. Reducing economic leakages from tourism: A value chain assessment of the tourism industry in Kasane, Botswana. Development Southern Africa 34:295-313.

USFWS (U.S. Fish and Wildlife Service). 2015. Endangered and threatened wildlife and plants; listing two lion subspecies. Final rule. Federal Register 2015-31958: 7999980056. Vucetich JA, Macdonald DW. 2017. Some essentials on co-existing with carnivores. Open Access Government August:216-217.

Wanger TC, Traill 1, Cooney R, Rhodes JR, Tscharntke T. 2017. Trophy hunting certification. Nature Ecology and Evolution 1:1791-1793. 